\title{
EDUCAÇÃO PROFISSIONAL E FORMAÇÃO INTEGRADA DO TRABALHADOR NA LEGISLAÇÃO BRASILEIRA: AVANÇOS, RETROCESSOS E DESAFIOS
}

\author{
R. F. AMORIM \\ Instituto Federal de Educação, Ciência e Tecnologia de Goiás \\ rodrigo123amorim@gmail.com *
}

Artigo submetido em outubro/2015 e aceito em dezembro/2015

DOI: $10.15628 /$ rbept.2016.3504

\section{RESUMO}

O presente artigo tem como objetivo analisar os avanços, retrocessos e desafios da concepção de formação integrada do trabalhador presente na legislação brasileira que versa sobre a educação profissional. Trata-se de uma pesquisa bibliográfica e documental que analisa as fontes primárias - legislação - a partir do enfoque teórico do campo trabalho-educação numa perspectiva crítica ao sistema capitalista a partir do materialismo histórico dialético e seus desdobramentos. Para isso, analisam-se os preceitos constitucionais, a Lei de Diretrizes e Bases da Educação Nacional, os decretos-lei que envolvem a educação profissional e as recentes proposições do Plano Nacional de Educação - PNE 2014-2024. Os resultados da análise demonstram que a formação integrada tem alcançado espaço na estrutura do sistema educacional brasileiro se constituindo, porém, como campo de disputas e contradições por projetos distintos de sociedade.

PALAVRAS-CHAVE: Educação profissional, Formação integrada, Formação do trabalhador, PNE 2014-2024.

\section{VACATION EDUCATION AND WORKER INTEGRED FORMATION IN THE BRAZILIAN LEGISLATION: PROGRESS, SETBACKS AND CHALLENGES}

\begin{abstract}
This article aims to analyze the progress, setbacks and challenges of designing integrated formation of the worker in the Brazilian legislation that deals with vocational education. It is a bibliographical and documentary research that analyzes the primary sources - legislation - from the theoretical approach of workeducation field in a critical perspective to the capitalist system from the dialectical historical materialism and its
\end{abstract}

aftermath. For this, analyzes the constitutional provisions, the Law of Guidelines and Bases of National Education, the decree-laws that involve education and the recent proposals of the National Education Plan - PNE 2014-2024. Test results demonstrate that integrated formation has reached space in the Brazilian educational system structure constituting, however, as a field of disputes and contradictions by different society projects 


\section{INTRODUÇÃO}

O presente artigo tem como objetivo discutir e analisar a temática da formação integrada do trabalhador a partir da leitura crítica dos documentos oficiais e legislação que regulamentam e normatizam a educação profissional brasileira, mediado por estudiosos do campo trabalho e educação que vem nas últimas décadas discutindo este tema, sobretudo, num sentido de luta política por um projeto de sociedade que coloque sobre o cidadão o direito de refletir e decidir que tipo de sociedade quer construir para além daquela que existe em função dos ditames do capital e de seu mercado de trabalho.

Autores como Machado e Oliveira (2010), Moura (2010), Frigotto, Ciavatta e Ramos (2012), Ferreira (2012), Ciavatta (2014) dentre outros, vem discutindo a relevância de uma formação integrada para o trabalhador que transponha as imposições da formação fragmentada e aligeirada exigida pelo mercado de trabalho regido sob as leis do capitalismo. Além dessa defesa, estes autores resgatam as concepções de uma educação pautada em princípios socialistas, como as discussões em torno do sentido do trabalho, da politecnia e da escola unitária postos na década de 1980 e início de 1990 (MACHADO, 1991; NOSELLA, 2010).

A sociedade atual, globalizada e conectada pelos ciberespaços da comunicação virtual e artificial, cada vez mais internacionalizada, não prescinde da necessidade de trabalhadores, pessoas - homens e mulheres - que se dediquem aos mais variados tipos de atividades, desde as mais rudimentares que não requerem mais do que o esforço físico e manual até as mais sofisticadas que requerem formação geral e aprofundamento científico e tecnológico. No entanto, o problema central que se discute neste trabalho é que esta forma de divisão social do trabalho, que classifica as pessoas para determinadas atividades, manuais e/ou intelectuais, de acordo com sua condição de escolarização, somente massifica a divisão social entre as classes antagonizando o trabalho manual versus o trabalho intelectual, com consequências diretas sobre o processo de formação dos trabalhadores, visto que aos interesses de atendimento das demandas do capital não é interessante a massificação de uma formação integrada, que recupere o acesso ao conhecimento da humanidade em suas diversas facetas e os apliquem à dimensão da formação profissional do trabalhador.

É preciso compreender, entretanto, que esse jogo de forças se constitui no palco da democracia, que no caso brasileiro, se constituiu como uma democracia restrita ${ }^{1}$ (FRIGOTTO; CIAVATTA; RAMOS, 2012) que excluiu as classes populares do direito de emancipação e participação cidadã das decisões políticas de seu país, legando às elites brasileiras o poder e o direito de exercerem sua liderança conforme seus interesses de manutenção do status quo e da posição de dominação que há muito vem exercendo sobre o Brasil.

\footnotetext{
${ }^{1}$ Marcos Arruda (2002), em seu artigo A articulação trabalho-educação visando uma democracia integral, denuncia que quanto mais repetitivas são as atividades de trabalho humano na sociedade, mais repetitivo tende a ser os processos educativos. Mas, a ruptura da compreensão do trabalho como tripalium (sofrimento, dor, cansaço) e a assunção do sentido mais amplo de trabalho, podem propiciar as condições de conscientização política do povo para a construção de uma democracia integral. Ele cita como no caso da Nicarágua, depois da revolução sandinista na década de 1980, o povo, consciente de seu papel histórico na sociedade, participou da constituinte para a elaboração de uma nova constituição que atendesse os anseios dos trabalhadores e colocasse o trabalho com princípio edificador da sociedade ao invés do capital.
} 
Foi no contexto desta democracia que se erigiu o "império" do capital em solo brasileiro, com forte marca de legitimação sobre a legislação que se constituiu no contexto democrático. A Constituição Federal (CF) de 1988, denominada de constituição cidadã, representa a legitimidade do contrato social que garantiu a legalidade da exploração do trabalho e a sustentação do sistema produtivo capitalista brasileiro. É neste espaço, democrático e contraditório, pois que advém de uma democracia restrita, que se consolidam as leis determinantes dos rumos da educação brasileira e, dentro desta, da educação profissional dos trabalhadores.

A partir desta compreensão crítica, de que o conjunto de leis e documentos que regem a educação profissional brasileira é fruto de um espaço de lutas, em que as classes dirigentes estão em contraposição às classes subalternizadas, é que são analisados os documentos e leis, entendoos como construções históricas inseridas num processo dialético que permite sua leitura crítica e a possibilidade de interpretações diversas, o que revela seu caráter contraditório, elemento fundamental para a dialética (GADOTTI, 1995).

\section{O QUE SIGNIFICA UMA FORMAÇÃO INTEGRADA DO TRABALHADOR?}

Pode-se iniciar esta discussão distinguindo-se a diferença entre formação integral e formação integrada. No contexto atual das políticas públicas em educação fala-se muito em educação de tempo integral das crianças e adolescentes. Isso está posto na Lei n.o 13.005, de 25 de junho de 2014, PNE 2014-2024², em sua meta 6 (seis): “oferecer educação em tempo integral em, no mínimo, cinquenta por cento das escolas públicas, de forma a atender, pelo menos, vinte e cinco por cento dos(as) alunos(as) da educação básica." Trata-se de uma formação integral que visa atingir seus sujeitos no desenvolvimento qualitativo de todas as suas dimensões pessoais: afetividade, corporeidade e racionalidade. Moll (2014) afirma que esta temática não é nova, advém da época do Manifesto dos Pioneiros da Educação Nova e, que, agora retoma o cenário de disputas políticas que envolvem a educação. A autora compreende que a defesa por uma escola de tempo integral e de qualidade é uma das formas de se superar o problema das desigualdades sociais e educacionais que marcam a história da sociedade brasileira.

Se a educação integral está posta para as pessoas em desenvolvimento, crianças e adolescentes, a educação ou formação integrada está posta para o trabalhador, que se encontra numa condição de exercício de atividades produtivas que requerem cada vez mais qualificação profissional. Aquela atua na constituição do ser em suas múltiplas dimensões, esta na formação do trabalhador de forma a integrá-lo critica e conscientemente no mundo do trabalho, no qual ele se constitui como sujeito criativo e não mero reprodutor de comandos.

Na concepção de Ciavatta (2012, p.84), a formação integrada tem como propósito fazer que:

[...] a educação geral se torne parte inseparável da educação profissional em todos os campos onde se dá a preparação para o trabalho: seja nos processos produtivos, seja nos processos educativos como a formação inicial, como o ensino técnico, tecnológico ou superior. Significa que buscamos enfocar o trabalho como princípio educativo, no sentido de superar a dicotomia trabalho manual / trabalho

\footnotetext{
${ }^{2}$ As próximas ocorrências do termo PNE 2014-2024 serão apresentadas na sua forma simples, PNE.
} 
intelectual, de incorporar a dimensão intelectual ao trabalho produtivo, de formar trabalhadores capazes de atuar como dirigentes e cidadãos.

Os fundamentos desta concepção têm bases históricas e conceituais nos termos da educação politécnica e omnilateralidade advindos das críticas que Marx faz ao sistema de produção capitalista. Neste sentido, a formação integrada transpõe o universo teórico da academia e se transforma em uma causa social e política a ser conquistada pelos trabalhadores e por aqueles que acreditam numa educação socialista como forma de emancipação e humanização dos seres humanos na construção de uma sociedade justa (CIAVATTA, 2014). Há um sentido de luta e mobilização presente no conceito de formação integrada, pois "busca-se contribuir para um futuro em que a superação da dualidade de classes sociais traga um padrão digno de vida e de conhecimento não apenas para as elites, mas também para os trabalhadores [...]" (Idem, p.202).

\section{COMO A FORMAÇÃO INTEGRADA (NÃO) ESTÁ POSTA NA LEGISLAÇÃO BRASILEIRA?}

Ciavatta (2014), Frigotto, Ciavatta e Ramos (2012), chamam atenção para os antecedentes históricos da década de 1980 e início de 1990 em que houve uma luta pela construção de uma legislação da educação brasileira que incorporasse o sentido da politecnia, da omnilateralidade, do trabalho como princípio educativo, da superação da divisão entre trabalho manual e intelectual, como fundamentos de uma educação emancipatória que ascendesse em poder as classes trabalhadoras com o objetivo de aproximá-las do acesso aos conhecimentos que a classe dominante já possuía ${ }^{3}$, e, consequentemente, transformando a realidade brasileira de exploração e desigualdades.

Compreendido estes pressupostos, o primeiro documento legal a ser analisado é a Constituição Federal de 1988, que não traz o termo "formação integrada" ou seus correlatos (politecnia, formação omnilateral, escola unitária, etc.). Ela priorizou a obrigatoriedade e gratuidade do ensino fundamental (Art.208) ${ }^{4}$, sem, contudo, assumir compromissos com o sentido da formação integrada. Apesar de defender a educação "visando ao pleno desenvolvimento da pessoa, seu preparo para o exercício da cidadania e sua qualificação para o trabalho" (Art.205), além de estabelecer a elaboração de um plano nacional que conduza o poder público à "formação para o trabalho" e a "promoção humanística, científica e tecnológica" (Art.214, incisos IV e V, respectivamente), a CF delineia um sentido ambíguo para o trabalho, pois não explicita sob que fundamentos a formação para o trabalho deverá ser desenvolvida. Se para atender exclusivamente ao mercado de trabalho e aos arranjos econômicos e/ou para atender ao cidadão como sujeito

\footnotetext{
${ }^{3}$ Estes princípios podem ser verificados no projeto de LDB de 1988, proposto pelo deputado Otávio Elísio, que estabelecia o objetivo do ensino médio: "propiciar aos adolescentes a formação politécnica necessária à compreensão teórica e prática dos fundamentos científicos das múltiplas técnicas utilizadas no processo produtivo." E, que posteriormente deve seu escopo ampliado pelo projeto substitutivo do deputado Jorge Hage. De acordo com Frigotto, Ciavatta e Ramos (2012) esse foi um percurso fértil e democrático malogrado pelo governo neoliberal que se constituiu nos anos de 1990 e, que, eclodiu com a aprovação da Lei no 9.394, de 20 de dezembro de 1996, atual LDB, na qual tais princípios e fundamentos foram postos de lado.

${ }^{4}$ A Emenda Constitucional no 59, de 11 de novembro de 2009, avançou no sentido de estender a obrigatoriedade e gratuidade para as pessoas entre quatro (4) e dezessete (17) anos de idade, incluindo o ensino médio.
} 
ativo na construção da sociedade por meio da produção dos bens materiais e imateriais que sustentam a coletividade.

Considerado o contexto histórico descrito pelos atores que participaram do movimento de redemocratização e abertura política (FRIGOTTO; CIAVATTA; RAMOS, 2012; CIAVATTA, 2014) a CF de 1988 , traduz bem o contexto de disputas e tensões que foi a questão do trabalho em sua relação com a educação.

Prevaleceu, portanto, na CF 1988, uma relação do trabalho com a educação que se pode designar como evasiva, provavelmente, uma tentativa de equacionar a disputa entre grupos divergentes e/ou o predomínio da visão dominante sob a influência do capital.

Se a CF 1988 não deixa isso claro, a Lei de Diretrizes e Bases da Educação (LDB), Lei no 9.394, de 20 de dezembro de 1996, segue o mesmo tom evasivo da carta magna. Sua primeira versão, sem as emendas posteriores, não oferece nenhuma defesa da formação integrada. O máximo que ela se digna fazer é repetir a mesma relação da educação com a formação para o trabalho preconizada pela CF, ao afirmar que a "a educação escolar deverá vincular-se ao mundo do trabalho e à prática social" (Art.1으, § 2ㅇ) com a finalidade de preparar para o exercício da cidadania e qualificação para o trabalho (Art.2º).

A questão fica ainda mais acirrada quando observados os artigos 35, 36 , 39 e 40, da LDB 9.394/96. O primeiro defende a finalidade do ensino médio, dentre outras, de preparar o educando para o trabalho e a cidadania "de modo a ser capaz de se adaptar com flexibilidade a novas condições de ocupação ou aperfeiçoamento posteriores" (grifos nosso); o segundo, ainda na seção do ensino médio, em seu $\S 4$ 으, afirmava que "a preparação geral para o trabalho e, facultativamente, a habilitação profissional, poderão ser desenvolvidas nos próprios estabelecimentos de ensino médio ou em cooperação com instituições especializadas em educação profissional" (grifos nosso); o terceiro, na seção da educação profissional, diz que esta deve conduzir o educando "ao permanente desenvolvimento de aptidões para a vida produtiva" (grifos nosso); e, o último, que a "educação profissional será desenvolvida em articulação com o ensino regular ou por diferentes estratégias de educação continuada, em instituições especializadas ou no ambiente de trabalho."

Diante disso, é preciso perguntar: o que significa formar o educando para se adaptar com flexibilidade às condições de ocupação e desenvolver aptidões para a vida produtiva? Qual a consequência de uma formação para o trabalho que deixa à cargo das escolas, públicas ou privadas, o elemento facultativo do "pode ser" desenvolvida uma formação para o trabalho no próprio estabelecimento de ensino médio? $E$, qual o sentido de se dizer que a educação profissional será desenvolvida em articulação com o ensino regular, se logo após a sentença está posto um "OU" que permite diferentes estratégias para sua execução? Num contexto de afirmação das políticas neoliberais da década de 1990, em particular, do governo de Fernando Henrique Cardoso (FHC) (CIAVATTA, 2014), esta permissividade da lei obviamente não poderia ser aproveitada a favor de uma formação integrada, cujas bases estão nos pressupostos de uma sociedade socialista, mas a favor do mercado de trabalho regido pelas leis da empregabilidade, flexibilidade, adaptabilidade, termos estes que os trabalhadores e estudantes deveriam se acostumar a perseguir como prática profissional que visasse o sucesso.

Se a LDB foi evasiva como o foi a CF 1988, quanto à temática da relação trabalho e educação na perspectiva de uma formação integrada, o ato posterior do chefe do executivo nacional nada 
teve de evasivo, foi diretivo e formal. Trata-se aqui do Decreto no 2.208, de 17 de abril de 1997, exarado pelo então presidente FHC.

Neste decreto, emite-se de forma clara e incisiva o compromisso do governo brasileiro com uma formação profissional desarticulada com a formação geral, princípio este norteado pelo neoliberalismo que minimiza o papel do Estado diante das políticas públicas de garantia dos direitos sociais, para atender à macroeconomia e exigências do mercado de trabalho. Uma leitura atenta de todo o decreto revela a separação posta entre escola e mundo do trabalho como condições de formação profissional, permitindo projetos de forma aligeirada cuja finalidade é o treinamento qualitativo do trabalhador para atender às demandas do mercado de trabalho.

Já no Art. 10, inciso I, a educação profissional tem entre seus objetivos a promoção da transição da "escola para o mundo do trabalho", o que significa uma visão de escola totalmente desarticulada do mundo do trabalho, dois elementos isolados e separados. Além disso, o mesmo inciso enfatiza que a capacitação de jovens e adultos com conhecimentos e habilidades é para o "exercício de atividades produtivas", o que põe uma interrogação sobre o sentido do que seja "produtivo". Que atividades são estas? Num contexto de internacionalização da economia e livre mercado, estas atividades produtivas só podem ser entendidas como empregos que promovem a afirmação do capitalismo como único sistema produtivo.

Entretanto, é o Art. 5ㅇ do Decreto n.o 2.208/97, que explicita de forma incisiva os pressupostos fundamentais da educação profissional do governo de FHC. Assim diz: "A educação profissional de nível técnico terá organização curricular própria e independente do ensino médio, podendo ser oferecida de forma concomitante ou sequencial a este." Aqui foi selada a separação entre formação básica e formação profissional. Mesmo que o Art. 20 afirmasse que a educação profissional fosse desenvolvida em articulação com o ensino regular, o Art. 5o bloqueou qualquer tentativa de articulação e integração, determinando a "organização curricular própria e independente" da educação profissional em relação ao ensino médio. Estava legitimada a formação por competências, termo este que aparece sete vezes no decreto.

Transcorrido o período de uma política de não formação integrada para o trabalhador, no governo Luís Inácio da Silva é revogado o Decreto n. 2.208/97 e exarado um novo - Decreto n. 5.154 , de 23 de julho de 2004 - que reabre a possibilidade de implementação da formação integrada na educação. De acordo com Frigotto, Ciavatta e Ramos (2012), dada a correlação de forças políticas e tendências decorrentes dos anos anteriores, a revogação de um decreto por outro com objetivos democráticos, ainda que contraditória em sua essência foi o caminho possível para garantir a "salvação" da matéria em termos legais e iniciar um novo processo de formação que já era ansiado deste a década de 1980.

Deste modo, o Decreto n. 5.154/2004 determina em seu Art. 4o que "a educação profissional técnica de nível médio [...], será desenvolvida de forma articulada com o ensino médio" (grifos nosso). Esta "forma articulada" havia se perdido no decreto anterior e, agora, é recuperada, evidenciando compromissos da agenda política do governo com um formato de formação profissional, se não independente da lógica do capital, pelo menos afirma a presença tensionada de uma nova perspectiva - a da formação integrada. Vale ressaltar também o direcionamento que é dado ao público de jovens e adultos trabalhadores, pois que em seu Art. 30 quando fala sobre a formação inicial e continuada dos trabalhadores define em seu § $2^{\circ}$ que, "os cursos mencionados no caput articular-se-ão, preferencialmente, com os cursos de educação de jovens e adultos, 
objetivando a qualificação para o trabalho e a elevação do nível de escolaridade do trabalhador [...]" (grifo do autor). Esta "elevação do nível de escolaridade do trabalhador" é um avanço que se destaca em relação ao decreto anterior, que simplesmente objetivava "qualificar, reprofissionalizar e atualizar jovens e adultos trabalhadores" sem compromisso com a elevação de sua escolaridade.

Com a Lei no 11.741, de 16 de julho de 2008, que reescreve os capítulos da educação profissional técnica de nível médio, da educação de jovens e adultos e da educação profissional e tecnológica, a formação integrada se transforma em uma possibilidade concreta com apoio legal para ser implementada no sistema educativo brasileiro. Diferentemente do decreto presidencial que é uma via emergencial e, de certa forma, "autoritária" do poder executivo através de seu chefe maior, a lei é fruto de um processo mais amplo e democrático, ainda que marcada pelos diversos interesses presentes no cenário político partidário da democracia brasileira, ainda restrita.

Dadas as condições legais para a implementação da formação integrada, o PNE reflete o contexto de disputas em torno da educação brasileira. Segundo Paulo Sena (2014), o processo de elaboração do PNE se aproximou com o da Constituinte de 1988, devido o grande número de atores participantes, setores públicos e privados, quanto pela quantidade de emendas - quase 3.000 !

É importante destacar estes elementos para que se perceba que o PNE é fruto de um processo histórico de lutas por interesses públicos e privados, que pressupõe visões específicas e distintas de homem, sociedade e educação. No caso da formação integrada, o PNE não traz explicitamente nenhum termo correlato (politecnia, formação omnilateral, escola unitária, etc.). Este silêncio, obviamente, pesa a favor da situação política, social e ideológica do país em que prevalecem modelos educacionais fortemente marcados pela subserviência aos valores do capitalismo.

Quando o PNE define suas diretrizes, e dentre elas, Art.2, inciso V, defende a "formação para o trabalho e para a cidadania, com ênfase nos valores morais e éticos em que se fundamenta a sociedade", isso ecoa em tom ambíguo porque os valores morais e éticos que fundamentam uma dada sociedade são construções históricas que atendem a interesses de classes que agem para a manutenção do poder.

Da análise das 20 metas do PNE e suas estratégias, três metas tangenciam a questão da formação integrada, são elas: Meta 3 - ensino médio, que na estratégia 3.7 decide "fomentar a expansão das matrículas gratuitas de ensino médio integrado à educação profissional"; Meta 10 educação de jovens e adultos, que na estratégia 10.2 afirma o compromisso de articular a EJA com a EP para aumentar a escolaridade do trabalhador e, na estratégia 10.3, "fomentar a integração" da EJA com a EP; e, Meta 11 - educação profissional técnica de nível médio, que na estratégia 11.9 afirma o compromisso de expandir o ensino médio integrado à EP para as populações do campo, indígenas e quilombolas.

Esses compromissos legais se constituem como política pública de Estado, que, se não garantem a formação integrada como totalidade da formação para o trabalhador, ao menos garantem legalmente a construção de caminhos para este projeto educacional. O que se percebe é que o PNE harmoniza-se com a legislação anterior - Decreto n.5.154/2004 e Lei n. 11.741/2008 - tanto em seus propósitos quanto em suas ambiguidades. Permanece a forma concomitante de 
articulação do ensino médio com a EP, bem como um ensino médio propedêutico, sem vinculação direta com a formação profissional.

Neste sentido, a Meta 8 que defende a elevação da escolaridade da população entre 18 e 29 anos de idade, em sua estratégia 8.4 ratifica o modelo concomitante quando defende a expansão da "oferta gratuita de educação profissional técnica por parte das entidades privadas de serviço social e de formação profissional vinculadas ao sistema sindical, de forma concomitante ao ensino ofertado na rede escolar pública, para os segmentos populacionais considerados" (grifos nosso). Importantíssima é análise de Moura (2010), sobre a forma concomitante, quando diz que ela "se encarregou de manter viva, no plano legal e prático, a dualidade estrutural entre EM [Ensino Médio] e EP [Educação Profissional]" (, p.882, acréscimos nosso). Este ponto é um sinal vívido da dificuldade de se caminhar para uma formação integrada do trabalhador, de corte revolucionário para a persistente dualidade estrutural da sociedade e do sistema educacional brasileiro.

\section{PARA FINALIZAR: AVANÇOS, RETROCESSOS E DESAFIOS}

Enfim, quais avanços, retrocessos e desafios podem ser identificados para uma formação integrada do trabalhador no contexto da educação profissional na legislação brasileira? O primeiro grande avanço é de ordem política, pois que em vista da luta dos anos de 1980 e 1990, em que as disputas por uma formação integrada foram malogradas pelo ideário neoliberal que se constituía naquele período, impediram a elaboração de leis que garantissem a articulação entre a formação geral e a profissional. Desta forma, com as novas leis exaradas a partir da década de 2000, novos horizontes são lançados sobre a educação profissional e sua articulação com a formação geral, possibilitando a retomada concreta e legal da formação integrada como ideário para a emancipação dos trabalhadores.

O segundo avanço é o institucional, pois a partir da retomada dos princípios da formação integrada, diversas medidas concretas foram tomadas para transformar a lei em realidade, dentre elas, talvez a mais expressiva de todas, foi o Programa de Expansão da Rede Federal de Educação Profissional e Tecnológica com a Lei n.11,892, de 29 de dezembro de 2008, que cria os Institutos Federais de Educação e Ihes obriga a oferta do ensino médio na forma integrada bem como a inserção da população de jovens e adultos por meio do Programa Nacional de Integração da Educação Profissional na Educação Básica na Modalidade de Educação de Jovens e Adultos (PROEJA).

Dentre os retrocessos, está a questão da permanência da concomitância entre a formação geral e a formação técnica em matrículas separadas e, até, instituições distintas, o que significa uma formação fragmentada que não alcança o objetivo de melhorar a escolaridade do trabalhador. Este elemento esteve presente no Decreto n. 5.154/2004, permaneceu na Lei n. 11.741/2008 e adentrou o PNE, persistindo os interesses políticos e ideológicos de uma formação do trabalhador desvinculada com a sua formação básica.

Por fim, o grande desafio proposto por esta análise recai sobre as questões políticopedagógicas. É nesse campo que se traduz os verdadeiros embates em torno da formação integrada. Trata-se do campo que envolve a gestão da escola e a prática pedagógica de professores e alunos. É neste espaço que se pode ou não construir práticas pedagógicas verdadeiramente integradas, alicerçadas na concepção de currículo integrado, projetos integradores, capazes de 
romper com a lógica de habilidades e competências pontuais que dispensam o pensamento crítico e o saber acumulado pela humanidade. É um desafio político pedagógico, porque não há ato pedagógico que não seja político e não há ação política que não seja pedagógica.

\section{REFERÊNCIAS}

1. ARRUDA, M. A articulação trabalho-educação visando uma democracia integra. In: GOMEZ, C. M. et al. Trabalho e conhecimento: dilemas na educação do trabalhador. 4. ed. São Paulo: Cortez, 2002.

2. BRASIL. Constituição (1988). Constituição da república federativa do Brasil. Brasília: Senado Federal, 2008.

3. BRASIL. Decreto $n$ o 2.208, de 17 de abril de 1997. Regulamenta o $\S 2$ o do art. 36 e os arts. 39 a 42 da Lei no 9.394, de 20 de dezembro de 1996... Brasília: Presidência da República, Casa Civil, Subchefia de Assuntos Jurídicos, 1997.

4. . Decreto $n$ o 5.154, de 23 de julho de 2004. Regulamenta o § 2ㅇ do art. 36 e os arts. 39 a 41 da Lei no 9.394, de 20 de dezembro de 1996... Brasília: Presidência da República, Casa Civil, Subchefia de Assuntos Jurídicos, 2009.

5. . Emenda Constitucional n.o 59, de 11 de novembro de 2009. Brasília: Presidência da República, Casa Civil, Subchefia de Assuntos Jurídicos, 2009. Disponível em: <http://www.planalto.gov.br/ccivil_03/constituicao/Emendas/Emc/emc59.htm>. Acesso em: 04 jun. 2015.

6. . Lei no 9.394, de 20 de dezembro de 1996. Brasília: Presidência da República, Casa Civil, Subchefia para Assuntos Jurídicos, 1996. Disponível em: <http://www.planalto.gov.br/ccivil_03/leis/19394.htm>. Acesso em: 04 jun. 2015.

7. L Lei no 11.892, de 29 de dezembro de 2008. Institui a Rede Federal de Educação Profissional, Científica e Tecnológica, cria os Institutos Federais de Educação, Ciência e Tecnologia, e dá outras providências. Brasília: Presidência da República, Casa Civil, Subchefia para Assuntos Jurídicos, 2008.

8. _. Plano nacional de educação 2014-2024: Lei no 13.005, de 25 de junho de 2014, que aprova o Plano Nacional de Educação (PNE) e dá outras providências. Brasília: Câmara dos Deputados, Edições Câmara, 2014.

9. CIAVATTA, M. O ensino integrado, a politecnia e a educação omnilateral. Por que lutamos? Trabalho \& Educação, Belo Horizonte, v.23, n.1, p.187-205, jan.-abr.2014.

10. FERREIRA, E. B. O PROEJA e o direito à formação integrada: limites, avanços e possibilidades de implantação. In: OLIVEIRA, E. C. de; PINTO, A. H.; FERREIRA, M. J. de R. Eja e educação profissional: desafios da pesquisa e da formação no Proeja. Brasília: Liber Livros, 2012. p.101120.

11. FRIGOTTO, G.; CIAVATTA, M.; RAMOS, M. N. Ensino médio integrado: concepção e contradições. 3. ed. São Paulo: Cortez, 2012.

12. GADOTTI, M. Concepção dialética da educação: um estudo introdutório. 9. ed. São Paulo: Cortez, 1995.

13. MACHADO, L. R. de S. Politecnia, escola unitária e trabalho. 2. ed. São Paulo: Cortez, Autores 
Associados, 1991.

14. MACHADO, M. M.; OLIVEIRA, J. F. de (Orgs.). A formação integrada do trabalhador: desafios de um campo em construção. São Paulo: Xamã, 2010.

15. MOLL, J. O PNE e a educação integral: desafios da escola de tempo completo e formação integral. Revista Retratos da Escola, Brasília, v.8, n.15, p.353-368, jul./dez. 2014. Disponível em: <http//www.esforce.org.br>. Acesso em: 03 jun.2015.

16. MOURA, D. H. A relação entre a educação profissional e a educação básica na CONAE 2010: possibilidades e limites para a construção do novo plano nacional de educação. Educação \& Sociedade, Campinas, v.31, n.112, p.875-984, jul.-set. 2010.

17. NOSELLA, P. A escola de Gramsci. 4. ed. São Paulo: 2010.

18. SENA, P. A história do PNE e os desafios da nova lei. In: BRASIL. Plano nacional de educação 2014-2024: Lei no 13.005, de 25 de junho de 2014, que aprova o Plano Nacional de Educação (PNE) e dá outras providências. Brasília: Câmara dos Deputados, Edições Câmara, 2014. 